\title{
Research Progress on the Mechanism of Cochlear Hair Cell Regeneration
}

\author{
Shan Xu and Ning Yang* \\ Department of Otolaryngology, The First Hospital of China Medical University, Shenyang, China
}

Mammalian inner ear hair cells do not have the ability to spontaneously regenerate, so their irreversible damage is the main cause of sensorineural hearing loss. The damage and loss of hair cells are mainly caused by factors such as aging, infection, genetic factors, hypoxia, autoimmune diseases, ototoxic drugs, or noise exposure. In recent years, research on the regeneration and functional recovery of mammalian auditory hair cells has attracted more and more attention in the field of auditory research. How to regenerate and protect hair cells or auditory neurons through biological methods and rebuild auditory circuits and functions are key scientific issues that need to be resolved in this field. This review mainly summarizes and discusses the recent research progress in gene therapy and molecular mechanisms related to hair cell regeneration in the field

OPEN ACCESS

Edited by: Zuhong He,

Wuhan University, China

Reviewed by: Yuhua Zhang,

Southeast University, China Wenwen Liu,

Shandong University, China

*Correspondence:

Ning Yang

ningyang0312@sina.com

Specialty section:

This article was submitted to Cellular Neuropathology, a section of the journal Frontiers in Cellular Neuroscience

Received: 29 June 2021 Accepted: 28 July 2021 Published: 20 August 2021

Citation: Xu S and Yang N (2021) Research Progress on the Mechanism of Cochlear Hair Cell Regeneration. Front. Cell. Neurosci. 15:732507. doi: 10.3389/fncel.2021.732507 of sensorineural hearing loss.

Keywords: inner ear, stem cell, hair cell, regeneration, sensorineural hearing loss

\section{INTRODUCTION}

Neural stem cells have the ability to self-renew and differentiate into various types of nerve cells and have been used as a potential treatment for various diseases. Some supporting cells with proliferation ability in the inner ear are also called sensory precursor cells (Monzack and Cunningham, 2013). Stem cell therapy refers to a treatment that uses the diversity of stem cells to induce differentiation into the same structure as the original shape and function when the normal structure of the organism is damaged or changed. This treatment can supplement the defective and damaged inner ear hair cells. The differentiation mechanism of inner ear stem cells is a complex regulatory network system. In addition to the expression sequence of genes playing an important role in the regulation of their differentiation, the secretion and interaction of various cytokines are also closely related to it. At present, the molecular regulation mechanism of inner ear stem cells is still unclear. With the increase of related research and the development of molecular biology technology, the molecular regulation mechanism of neural stem cell differentiation has gradually been elucidated. In recent years, the inner ear sensory precursor cells or stem cells are induced to re-enter the cell cycle by activating the inner ear-related signal pathways, and proliferate and differentiate into hair cells, and finally restore hearing or vestibular function, which have gradually become a research hotspot (Monzack and Cunningham, 2013). The proliferation and differentiation of sensory precursor cells are regulated by various related signal pathways, including

Abbreviations: AAV, adeno-associated virus; AAV-ie, AAV-inner ear; CDK, cycl-dependent protein kinase; BMP4, bone morphogenetic protein 4; DKK, Dickkopf; mTORC1, Akt-mTOR complex 1; Dnmt, DNA methyltransferase. 
WNT, Notch, BMP/Smad, FGF, IGF, and Shh signal pathways (Schimmang, 2007; Munnamalai and Fekete, 2016; Waqas et al., 2016; Wu et al., 2016). The regulation of these signal pathways and related factors is very important for the induction of inner ear stem cells and sensory precursor cells to differentiate into mature inner ear hair cells.

In recent years, with the in-depth research on the pathogenesis of deafness, more and more researchers are trying to treat hearing diseases through stem cell therapy. At present, there are two main ways to regenerate hair cells in the inner ear: one is that the supporting cells will re-enter the cell cycle and differentiate into hair cells after mitosis. Another way is that supporting cells will directly transdifferentiate into hair cells. In addition to Sox ${ }^{+}$cells, $\operatorname{Lgr} 5^{+}$cells, and Axin2 ${ }^{+}$ cells that are often used for stem cell research, Chai et al. (2012) found that the cell population of Fzd9 ${ }^{+}$cells is much smaller than Lgr5 ${ }^{+}$progenitor cells in the cochlea of newborn Fzd9-CreER/Rosa26-tdTomato mice (Zhang et al., 2019). They also found that $\mathrm{Fzd} 9^{+}$cells have the ability to generate hair cells in vivo. In addition, the proliferation, differentiation, and hair cell generation capabilities of $\mathrm{Fzd} 9{ }^{+}$cells cultured in vitro are similar to those of $\mathrm{Lgr5}^{+}$progenitor cells. Therefore, Fzd9 ${ }^{+}$ cells may be the main functional progenitor cell type in Lgr5 ${ }^{+}$ cells (Zhang et al., 2019). Therefore, Fzd9 can be used as a marker for hair cell progenitor, which is more specific than Lgr5 in hair cell progenitor.

\section{APPLICATION OF AAV VECTORS IN INNER EAR}

The method of regulating the differentiation and development of stem cells through gene editing to promote the regeneration of inner ear hair cells has gradually become a research hotspot in the field of hearing. The ideal vector for gene editing needs to accurately deliver the nucleic acid fragments into the inner ear and target cells and express them efficiently. In addition, the vector needs to have high transfection efficiency, controllable intensity and time, and high safety. Traditional viral vectors are toxic and carry limited gene capacity. In recent years, researchers have discovered some ideal adeno-associated virus $(\mathrm{AAV})$ vectors that can be transfected in the inner ear (Iizuka et al., 2008; Giannelli et al., 2018; Gu et al., 2019; Tan et al., 2019). AAV vector-mediated gene therapy has been approved in the United States and can be used to treat rare hereditary eye diseases (Tan et al., 2019). Omar Akil et al. have used the AAV virus vector to deliver the VGLUT3 gene to VGLUT3 knockout mice and achieved significant improvement in hearing (Akil et al., 2012). In order to avoid the shortcomings of low efficiency of traditional AAVs infecting outer hair cells, Zinn et al. made the vector AAV2/Anc80L65 based on the original sequence of the AAV capsid (Zinn et al., 2015). This vector can efficiently target the inner hair cells and outer hair cells of the cochlea, which indicates an important breakthrough in the research of AAV vectors in cochlear cell targeting. Kevin and colleagues found that AAV2.7m8 can also efficiently infect inner hair cells and outer hair cells in the cochlea, and the efficiency of infecting outer hair cells is even higher than that of Anc80L65
(Gu et al., 2019; Isgrig et al., 2019). In addition, AAV2.7m8 not only preferentially targets cochlear hair cells, but it can also efficiently infect $\operatorname{Lgr} 5^{+}$supporting cells. Tan et al. constructed the AAV mutant AAV-inner ear (AAV-ie) by inserting the polypeptide DGTLAVPFK, which can increase the infection efficiency by generating a transmembrane structure (Tan et al., 2019). AAV-ie can efficiently infect cochlear hair cells and vestibular hair cells. In the cochlea, since GFAP protein is expressed in supporting cells but not in hair cells, the GFAP promoter can be used to achieve specific expression of AAV-ie genes in supporting cells. In addition, studies have found that $\mathrm{AAV}$-ie does not affect the function of hair cells and the auditory system (Tan et al., 2019).

\section{SIGNAL PATHWAYS RELATED TO HAIR CELL REGENERATION}

In recent years, researchers have discovered through the study of related pathways in the inner ear that WNTs, FGFs, BMP, Shh, Notch, and other signaling molecules play different roles in the process of hair cell regeneration (Figure 1). Therefore, hair cell regeneration does not depend on the activation of one signal pathway but is coordinated by multiple signal pathways.

\section{The Role of Wnt Signaling Pathway in Hair Cell Regeneration}

The WNT/ $\beta$-catenin signaling pathway plays an important regulatory role in cell proliferation, cell fate determination, and hair cell differentiation (Jacques et al., 2014). When the $\mathrm{WNT} / \beta$-catenin signal is inhibited, the proliferation ability of sensory cells is reduced, and the activation of the WNT/Bcatenin signal promotes the increase of hair cells (Jacques et al., 2012; Shi et al., 2014). The target genes Lgr5 and Lgr6 of the WNT pathway are expressed in embryonic and neonatal cochlear progenitor cells (Chai et al., 2011; Samarajeewa et al., 2019). Lgr5 $^{+}$cells have the characteristics of hair cell progenitor cells, such as proliferation, self-renewal, and regeneration into hair cells (Chai et al., 2012; Shi et al., 2012; Cox et al., 2014; Wang et al., 2015). After WNT agonist treatment, the proliferation ability of the Lgr5 ${ }^{+}$progenitor cells of the neonatal mouse cochlea and their ability to differentiate into hair cells were enhanced (Romero-Carvajal et al., 2015; Samarajeewa et al., 2019). WNT agonists or overexpression of $\beta$-catenin can increase the proliferation of $\mathrm{Lgr}^{+}$progenitor cells and promote the formation of hair cells, while WNT antagonists inhibit the proliferation of $\mathrm{Lgr}^{+}$cells and the ability to regenerate hair cells (Chai et al., 2012; Shi et al., 2012, 2013). In newborn mice, the activation of WNT signaling can also cause Axin2positive cells to proliferate and differentiate into hair cells and supporting cells (Jan et al., 2013). When the expression of $\beta$ catenin and Atoh1 are activated simultaneously, the proliferation ability and the directed differentiation ability of Lgr ${ }^{+}$cells into hair cells and the survival ability of newly regenerated hair cells are enhanced (Kuo et al., 2015; Mittal et al., 2017). In addition, the combination of WNT signal activation and Notch signal inhibition in the cochlea of newborn mice has also been 


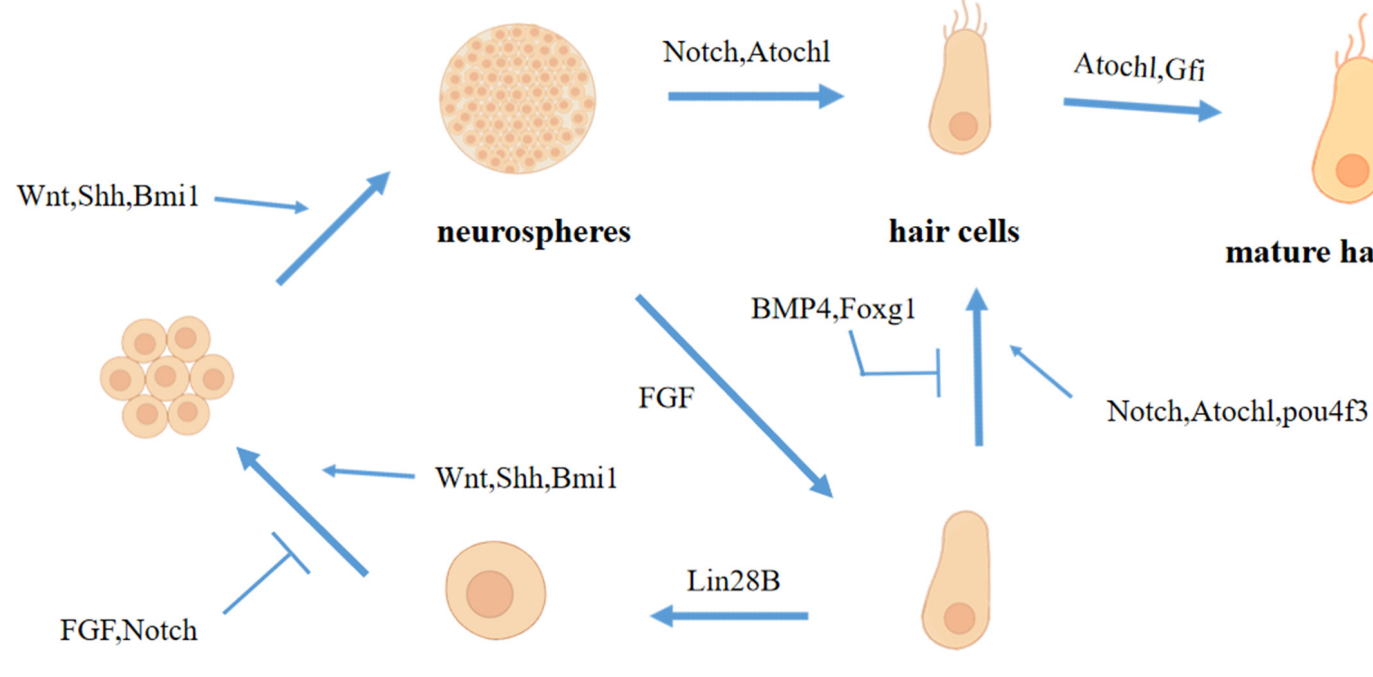

inner ear stem cells supporting cells

FIGURE 1 | The role of various signal pathways and related factors in the process of hair cell regeneration.

shown to promote the proliferation of supporting cells and the regeneration of hair cells ( $\mathrm{Ni}$ et al., 2016).

\section{The Role of Notch Signaling Pathway in Hair Cell Regeneration}

The Notch signaling pathway plays an important role in the development and regeneration of hair cells. Supporting cells are induced to transdifferentiate into hair cells when Notch signaling in the cochlea of newborn mice is suppressed (Yamamoto et al., 2006; Mizutari et al., 2013; Bramhall et al., 2014). Researchers found that activating the Notch pathway in supporting cells puts them in a quiescent state and inhibits hair cell regeneration ( $\mathrm{Ma}$ et al., 2008; Daudet et al., 2009). Previous studies found that in the cochlea of neonatal mammals, the expression of Atoh1 was up-regulated after $\gamma$-secretase inhibitor blocked the Notch signal, and caused the adjacent supporting cells to transdifferentiate into hair cells. However, this newly generated hair cell does not have the characteristics of a mature hair cell (Korrapati et al., 2013; Mizutari et al., 2013). In addition, knocking out Hes1 and Hes 5 members of the Hes family with siRNA can also up-regulate the expression of Atoh1, leading to an increase in the number of hair cells in the cochlea of newborn and adult mice (Du et al., 2018). Conditional inhibition of Notch signal can accelerate Lgr5 ${ }^{+}$cells in supporting cells to become new hair cells (Mittal et al., 2017). Co-activating the cell cycle activator Myc and Notch1 in the inner ear can induce the proliferation of different types of cochlear sensory epithelial cells. After the cochlear supporting cells are reprogrammed by regulating the activity of MYC/NICD, Atoh1 can induce the supporting cells in vivo and in vitro to effectively transdifferentiate into hair cell-like cells (Shu et al., 2019). Li et al. (2015) found that the combined inhibition of WNT and Notch signals can reduce the generation of hair cells, indicating that the progenitor cell proliferation phenomenon that occurs after Notch inhibition is mainly regulated by the WNT pathway ( $\mathrm{Li}$ et al., 2015).

\section{The Role of Hedgehog Signaling Pathway in Hair Cell Regeneration}

The Hedgehog pathway is a highly conserved signaling pathway, which plays an important role in regulating the proliferation and cell fate determination and differentiation of progenitor cells in the early developmental stage of the inner ear (Zarei et al., 2017). Previous studies have found that inactivation of Hedgehog signaling causes abnormal proliferation and differentiation of mammalian cochlear cells, leading to abnormal development of cochlear structure and function (Brown and Epstein, 2011; Bok et al., 2013; Son et al., 2015). Lu et al. (2013) found that after neomycin damage, Shh signaling may inhibit the function of $\mathrm{pRb}$ to promote sensory epithelial cells in the cochlea of newborn mice to re-enter the cell cycle and regenerate into new hair cells. Chen et al. (2017) found that recombinant Shh protein can effectively promote the proliferation and differentiation of Lgr5 ${ }^{+}$progenitor cells in the cochlea of newborn mice. In addition, after R26-SmoM2 mouse cochlear explants are treated with neomycin, Hedgehog signal activation can significantly promote cochlear epithelial cell proliferation and hair cell regeneration (Chen et al., 2017).

\section{The Role of FGF Signaling Pathway in Hair Cell Regeneration}

The FGF signaling pathway activates the gene regulatory network of the early development of the inner ear and induces the formation of the pre-placodal region and the auditory placode (Padanad et al., 2012; Ornitz and Itoh, 2015). In addition, the FGF signaling pathway plays a key role in the spontaneous 
regeneration of lower vertebrate hair cells and the induction and differentiation of stem cells into hair cells. $\mathrm{Ku}$ et al. found that when the chicken utricle was damaged by ototoxic drugs, the decrease of FGF expression level promoted the proliferation of supporting cells ( $\mathrm{Ku}$ et al., 2014). Jiang et al. found that the inhibition of the FGF and Notch pathway in the process of supporting cell proliferation is consistent with the down-regulation of the cycl-dependent protein kinase (CDK) inhibitor CDKN1b (p27/kip1; Jiang et al., 2014). Therefore, the inhibition of FGF and Notch signaling pathway is the triggering factor for supporting cell proliferation. Piotrowski et al. found through scRNA-seq that the deletion of Fgf3 expression in zebrafish supporting cells resulted in enhanced hair cell regeneration and increased the number of cells in neuromast (Lush et al., 2019). Lee et al. (2016) used drugs and genes to block FGF signaling and found that inhibiting FGF signaling can significantly inhibit the regeneration of hair cells in neuromast. Tang et al. found that the FGF signaling pathway and WNT signaling pathway have a coordinated regulatory effect on the proliferation of zebrafish lateral line cells (Tang et al., 2019). When the FGF signal is inhibited, the WNT pathway-mediated cell proliferation will also be inhibited. In the absence of WNT activity, activating the FGF signal with bFGF will restore part of supporting cell proliferation and hair cell regeneration.

\section{TRANSCRIPTION FACTORS RELATED TO HAIR CELL REGENERATION}

Atoh1 is a transcription factor with a helix-loop-helix structure, which is essential for the differentiation of hair cells during the development of the inner ear (Bermingham et al., 1999). In animal experiments, it was found that the sensory epithelium of the cochlea of Atoh1 knockout mice differentiated into supporting cells, but not cochlear hair cells and vestibular hair cells (Chen et al., 2002). Therefore, Atoh1 gene is an essential transcription factor in the process of hair cell generation. In in vitro experiments, researchers found that activating the expression of Atoh1 in the cochlea or vestibular sensory epithelium can induce hair cell regeneration (Bermingham et al., 1999; Izumikawa et al., 2005; Gubbels et al., 2008; Liu et al., 2012). In damaged mouse utricle, overexpression of Atoh1 can induce the proliferation of supporting cells and promote them transdifferentiate into hair cell-like cells (Jen et al., 2019). In addition, the overexpression of Atoh 1 also caused the up-regulation of many hair cell-related genes but did not include the hair cell maturation-related genes. Cheng found that the expression of Atoh1 in prenatal rats can induce supporting cells to differentiate into sensory hair cells, but the regenerated hair cells are immature, which may be due to the absence of Atoh1 down-regulation during hair cell development (Cheng, 2019). Therefore, hair cell regeneration and maturation are not only regulated by Atoh1, but also coordinated by other transcription factors.

Gfil is one of the GPS (Gfil/pag3/SENS) family transcription factors with a zinc finger domain. During the development of the inner ear, Gfil plays an important role in the normal differentiation, survival, and maturation of hair cells (Wallis et al., 2003). Gfil expression-deficient mice showed abnormal hair cell development, such as cochlear outer hair cells and inner hair cells degenerating from the basal turn to the apex turn until they were completely absent (Wallis et al., 2003; Li and Doetzlhofer, 2020). Matern et al. found that when Gfil expression is absent, the maturation of hair cells in the cochlea and vestibule is blocked, and the expression of hair cell maturation markers, such as Strc, Tmc1, and Ocm, is inhibited (Matern et al., 2020). Lee et al. found that Gfil and upstream Atoh1 coordinately regulate the regeneration of cochlear hair cells in newborn mice (Lee et al., 2020).

The secreted protein bone morphogenetic protein 4 (BMP4) can regulate inner ear morphogenesis and hair cell development. Lewis et al. found that when the cochlea cultured in vitro is damaged, the addition of BMP4 can inhibit the expression of Atoh1 in supporting cells, thereby inhibiting supporting cell mitosis and hair cell regeneration (Lewis et al., 2018). After treatment with the BMP4 inhibitor noggin, the number of regenerated hair cells increased (Lewis et al., 2018).

Bmil is a member of the Polycomb protein family and plays a regulatory role in the proliferation of progenitor cells and stem cells in multiple organs (Bruggeman et al., 2007; LópezArribillaga et al., 2015; Lu et al., 2017). Recently, researchers have discovered that Bmil activates WNT signaling by inhibiting the Dickkopf (DKK) family with WNT inhibitor functions (Cho et al., 2013). Lu et al. (2017) demonstrated in in vitro experiments that knocking out Bmil can significantly inhibit the proliferation of $\mathrm{Lgr}^{+}$progenitor cells in the cochlea of neonatal mice after neomycin damage. Compared with wild-type mice, the expression of DKK1 in $\mathrm{Bmil}^{-/-}$neonatal mice was significantly up-regulated, while the expression of $\beta$-catenin and Lgr5 was significantly down-regulated. In addition, the WNT agonist BIO inhibited the decline of the proliferation ability of $\mathrm{Bmil}^{-/-}$mouse supporting cells, indicating that Bmil affects the proliferation of supporting cells and Lgr5 ${ }^{+}$ progenitor cells through the regulation of WNT signaling pathway. Therefore, Bmil may be a new therapeutic target for hair cell regeneration.

The POU domain transcription factor Pou4f3 plays an important role in the development of inner ear hair cells (Masuda et al., 2011). Recent studies have found that in the adult mouse cochlea, the ectopic expression of Pou4f3 can promote the transdifferentiation of supporting cells into hair cells together with Atoh1 (Walters et al., 2017). The activation of downstream target genes by Pou4f3 can promote Atoh1mediated hair cell development and survival (Walters et al., 2017). Pou4f3 not only regulates the expression of Gfil and $\mathrm{Nr} 2 \mathrm{f} 2$ related to hair cell regeneration (Zhong et al., 2019) but also is the direct target gene of Atoh1 during hair cell development (Lee et al., 2020). Atoh1-Pou4f3-target gene (such as Gfi1) is not only an important molecular pathway for regulating the fate and differentiation of hair cells but also an important molecular pathway for hair cell maturation and survival. Therefore, POU4f3 as a therapeutic target, activating its activity alone or coordinating with Atoh1 may promote the regeneration of auditory hair cells. 
Foxg1 is one of the forkhead box genes involved in morphogenesis, cell fate determination, and proliferation. Previous studies reported that Foxg1 is necessary for the morphogenesis of the inner ear in mammals (Pauley et al., 2006; Hwang et al., 2009; He et al., 2018). Pauley et al. found that in Foxg1 knockout mice, the cochlear duct became shorter, the number of hair cells increased, the vestibule shrank, the growth of axons, and the distribution of vestibular neurons were abnormal (Pauley et al., 2006). Chai et al. (2012) found that conditionally knocking out Foxg1 in Sox ${ }^{+}$supporting cells and $\mathrm{Lgr}^{+}$progenitor cells of newborn mice induced these cells to transdifferentiate into hair cells, resulting in a significant increase in the number of hair cells and a significant decrease in supporting cells (Zhang et al., 2020). In addition, they also found that knocking out Foxg1 expression down-regulated the expression of several Notch signaling pathway factors such as Hes1, Hes5, and Hey1. At the same time, the expression of cell cycle-dependent kinase (Cdk2) was also down-regulated, while the expression of cell cycle repressors Cdkn1c, Cdkn2a, and Gadd45g were up-regulated, indicating that Foxg1 knockout may cause cell cycle and Notch signaling pathway to be inhibited, which led to the increase of hair cells (Zhang et al., 2020). Chai et al. (2012) also found that knocking out Foxg1 in Sox $9^{+}$supporting cells can promote the transdifferentiation of supporting cells into hair cells in neonatal mouse utricle (Zhang et al., 2020). The above studies provide evidence for the role of Foxg1 in the regeneration of cochlear hair cells in newborn mice.

The Lin28 gene encodes an evolutionarily highly conserved RNA binding protein, which is known to regulate the larval development time of Caenorhabditis elegans (Moss and Tang, 2003). In humans and mice, Lin28a and its homolog Lin28b are key regulators of organ growth, metabolism, tumorigenesis, and tissue repair (Ambros and Horvitz, 1984; Shyh-Chang and Daley, 2013). Doetzlhofer and colleagues found that the pathway composed of Lin $28 b$ and let-7 miRNAs regulates the generation of new hair cells in P2 mouse cochlear explants (Golden et al., 2015). The role of $\operatorname{Lin} 28 b$ is mainly to promote the generation of new hair cells, while the role of let-7 miRNAs is to inhibit the generation of new hair cells. Lin28b functional defect or overexpression of let- $7 \mathrm{~g}$ miRNAs leads to the inhibition of the activity of Akt-mTOR complex 1 (mTORC1) so that immature supporting cells cannot be transdifferentiated into hair cells ( $\mathrm{Li}$ and Doetzlhofer, 2020). On the contrary, overexpression of Lin28b increased the activity of AktmTORC1, and dedifferentiated the maturing supporting cells into progenitor-like cells, and generated hair cells through mitotic and non-mitotic mechanisms (Li and Doetzlhofer, 2020). These findings may provide new strategies for future hair cell regeneration treatments.

In addition, Menendez et al. (2020) found that the combination of four transcription factors (Six1, Atoh1, Pou4f3, and Gfil) can transdifferentiate neonatal mouse supporting cells (P8), mouse embryonic fibroblasts, and adult mouse tail fibroblasts into induced hair cells (IHCs). IHCs have various characteristics of hair cells, such as morphology, transcriptome and epigenetic characteristics, electrophysiological characteristics, mechanosensory channel expression, and ototoxin susceptibility. Therefore, IHCs can be used as an ideal in vitro model for studying hair cell function, maturation, regeneration, and ototoxin sensitivity.

\section{THE ROLE OF EPIGENETIC REGULATION OF HAIR CELL REGENERATION}

Epigenetic modification plays an important role in the development of the inner ear, and recent studies have found that it also has an important regulatory role in hair cell regeneration. During the development of zebrafish larvae, the inhibition of LSD1 by 2-PCPA decreased the expression of $W N T / \beta$ catenin and FGF signaling pathways, thereby significantly inhibiting the regeneration of supporting cells and hair cells after neomycin damage (He et al., 2016). The inhibition of G9a/GLP by BIX01294 significantly reduced the dimethylation of H3K9 in the zebrafish lateral line (Tang et al., 2016). The defect of H3K9me2 significantly inhibited the WNT/ $\beta$ catenin and FGF signaling pathways, which significantly reduced the proliferation of supporting cells after neomycin damage, and ultimately lead to the reduction of mitotic regeneration of hair cells in the zebrafish lateral line (Tang et al., 2016). Previous studies have found that when 5-azacytidine, a DNA methyltransferase (Dnmt) inhibitor, is injected into the cochlea of mature mice that are chemically deafened, DNA demethylation may promote the regeneration of hair cells in the cochlea of mature mice (Deng and $\mathrm{Hu}, 2020$ ). The advantage of this epigenetic method is that the DNA sequence remains unchanged during the process without integrating the exogenous DNA sequence.

\section{CONCLUSION}

There are various ways and mechanisms that cause sensorineural hearing loss, among which irreversible damage to inner ear hair cells is the main cause of sensorineural hearing loss. Although the commonly used hearing aids and cochlear implants in clinical practice also improve the hearing of patients, their effect depends on the quantity and quality of residual hair cells and spiral neurons. Therefore, the ideal way to treat sensorineural hearing loss is to regenerate hair cells through stem cells to repair the structure and function of the cochlea so as to fundamentally restore hearing. Stem cell therapy in the auditory field has been a research hotspot in recent years. Although some progress has been made, almost all are results at the animal level, and there is still a long way to go before clinical transformation. The microenvironment of inner ear stem cells and the interaction with neighboring cells are very important for inner ear stem cells or sensory precursor cells to induce differentiation into mature inner ear hair cells. In the reported studies, the efficiency of differentiation of inner ear stem cells or sensory precursor cells into hair cells is still low. An insufficient number of new hair cells, immature new hair cells without the function of mature hair cells, and long-term survival of new hair cells are all key 
problems and difficulties that need to be solved urgently. All these indicate that it is more difficult to regulate a single signal pathway to regenerate functional hair cells, and it may require coordinated regulation of multiple genes to effectively promote hair cell regeneration and the functional maturity and survival of new hair cells. At present, inducing the committed differentiation of stem cells into hair cells or nerve cells, the exploration of the methods of stem cell transplantation into the

\section{REFERENCES}

Akil, O., Seal, R. P., Burke, K., Wang, C., Alemi, A., During, M., et al. (2012). Restoration of hearing in the VGLUT3 knockout mouse using virally mediated gene therapy. Neuron 75, 283-293. doi: 10.1016/j.neuron.2012. 05.019

Ambros, V., and Horvitz, H. R. (1984). Heterochronic mutants of the nematode Caenorhabditis elegans. Science 226, 409-416. doi: 10.1126/science.6494891

Bermingham, N. A., Hassan, B. A., Price, S. D., Vollrath, M. A., Ben-Arie, N., Eatock, R. A., et al. (1999). Math1: an essential gene for the generation of inner ear hair cells. Science 284, 1837-1841. doi: 10.1126/science.284.54 21.1837

Bok, J., Zenczak, C., Hwang, C. H., and Wu, D. K. (2013). Auditory ganglion source of Sonic hedgehog regulates timing of cell cycle exit and differentiation of mammalian cochlear hair cells. Proc. Natl. Acad. Sci. U S A 110, 13869-13874. doi: 10.1073/pnas. 1222341110

Bramhall, N. F., Shi, F., Arnold, K., Hochedlinger, K., and Edge, A. S. B. (2014). Lgr5-positive supporting cells generate new hair cells in the postnatal cochlea. Stem Cell Rep. 2, 311-322. doi: 10.1016/j.stemcr.2014.01.008

Brown, A. S., and Epstein, D. J. (2011). Otic ablation of smoothened reveals direct and indirect requirements for Hedgehog signaling in inner ear development. Development (Cambridge, England) 138, 3967-3976. doi: 10.1242/dev.066126

Bruggeman, S. W. M., Hulsman, D., Tanger, E., Buckle, T., Blom, M., Zevenhoven, J., et al. (2007). Bmil controls tumor development in an Ink4a/Arf-independent manner in a mouse model for glioma. Cancer Cell 12, 328-341. doi: 10.1016/j.ccr.2007.08.032

Chai, R., Kuo, B., Wang, T., Liaw, E. J., Xia, A., Jan, T. A., et al. (2012). Wnt signaling induces proliferation of sensory precursors in the postnatal mouse cochlea. Proc. Natl. Acad. Sci. U S A 109, 8167-8172. doi: 10.1073/pnas. 1202774109

Chai, R., Xia, A., Wang, T., Jan, T. A., Hayashi, T., Bermingham-McDonogh, O., et al. (2011). Dynamic expression of Lgr5, a Wnt target gene, in the developing and mature mouse cochlea. J. Assoc. Res. Otolaryngol. 12, 455-469. doi: 10.1007/s10162-011-0267-2

Chen, P., Johnson, J. E., Zoghbi, H. Y., and Segil, N. (2002). The role of Math1 in inner ear development: uncoupling the establishment of the sensory primordium from hair cell fate determination. Development 129, 2495-2505. doi: 10.3410/f.1006295.78812

Chen, Y., Lu, X., Guo, L., Ni, W., Zhang, Y., Zhao, L., et al. (2017). Hedgehog signaling promotes the proliferation and subsequent hair cell formation of progenitor cells in the neonatal mouse cochlea. Front. Mol. Neurosci. 10:426. doi: 10.3389/fnmol.2017.00426

Cheng, Y.-F. (2019). Atoh1 regulation in the cochlea: more than just transcription. J. Zhejiang Univ. Sci. B. 20, 146-155. doi: 10.1631/jzus.B1600438

Cho, J.-H., Dimri, M., and Dimri, G. P. (2013). A positive feedback loop regulates the expression of polycomb group protein BMI1 via WNT signaling pathway. J. Biol. Chem. 288, 3406-3418. doi: 10.1074/jbc.M112.422931

Cox, B. C., Chai, R., Lenoir, A., Liu, Z., Zhang, L., Nguyen, D.-H., et al. (2014). Spontaneous hair cell regeneration in the neonatal mouse cochlea in vivo. Development 141, 816-829. doi: 10.1242/dev.103036

Daudet, N., Gibson, R., Shang, J., Bernard, A., Lewis, J., and Stone, J. (2009). Notch regulation of progenitor cell behavior in quiescent and regenerating auditory epithelium of mature birds. Dev. Biol. 326, 86-100. doi: 10.1016/j.ydbio.2008. 10.033

Deng, X., and Hu, Z. (2020). Generation of cochlear hair cells from Sox2 positive supporting cells via DNA demethylation. Int. J. Mol. Sci. 21:8649. doi: $10.3390 /$ ijms 21228649 inner ear, and the safety research of stem cell transplantation have laid the foundation for the transplantation of stem cells in vivo.

\section{AUTHOR CONTRIBUTIONS}

SX and NY wrote the article. All authors contributed to the article and approved the submitted version.

Du, X., Cai, Q., West, M. B., Youm, I., Huang, X., Li, W., et al. (2018). Regeneration of cochlear hair cells and hearing recovery through Hes1 modulation with siRNA nanoparticles in adult guinea pigs. Mol. Ther. 26, 1313-1326. doi: 10.1016/j.ymthe.2018.03.004

Giannelli, S. G., Luoni, M., Castoldi, V., Massimino, L., Cabassi, T., Angeloni, D., et al. (2018). Cas9/sgRNA selective targeting of the P23H Rhodopsin mutant allele for treating retinitis pigmentosa by intravitreal AAV9.PHP.B-based delivery. Hum. Mol. Genet. 27, 761-779. doi: 10.1093/hmg/ddx438

Golden, E. J., Benito-Gonzalez, A., and Doetzlhofer, A. (2015). The RNA-binding protein LIN28B regulates developmental timing in the mammalian cochlea. Proc. Natl. Acad. Sci. U S A 112, E3864-E3873. doi: 10.1073/pnas.1501077112

Gu, X., Chai, R., Guo, L., Dong, B., Li, W., Shu, Y., et al. (2019). Transduction of adeno-associated virus vectors targeting hair cells and supporting cells in the neonatal mouse cochlea. Front. Cell. Neurosci. 13:8. doi: 10.3389/fncel.2019. 00008

Gubbels, S. P., Woessner, D. W., Mitchell, J. C., Ricci, A. J., and Brigande, J. V. (2008). Functional auditory hair cells produced in the mammalian cochlea by in utero gene transfer. Nature 455, 537-541. doi: 10.1038/nature07265

He, Y., Tang, D., Cai, C., Chai, R., and Li, H. (2016). LSD1 is required for hair cell regeneration in zebrafish. Mol. Neurobiol. 53, 2421-2434. doi: 10.1007/s12035015-9206-2

He, Z., Fang, Q., Li, H., Buwei, S., Zhang, Y., Zhang, Y., et al. (2018). The role of FOXG1 in the postnatal development and survival of mouse cochlear hair cells. Neuropharmacology 144, 43-57. doi: 10.1016/j.neuropharm.2018.10.021

Hwang, C. H., Simeone, A., Lai, E., and Wu, D. K. (2009). Foxg1 is required for proper separation and formation of sensory cristae during inner ear development. Dev. Dyn. 238, 2725-2734. doi: 10.1002/dvdy.22111

Iizuka, T., Kanzaki, S., Mochizuki, H., Inoshita, A., Narui, Y., Furukawa, M., et al. (2008). Noninvasive in vivo delivery of transgene via adeno-associated virus into supporting cells of the neonatal mouse cochlea. Hum. Gene Ther. 19, 384-390. doi: 10.1089/hum.2007.167

Isgrig, K., McDougald, D. S., Zhu, J., Wang, H. J., Bennett, J., and Chien, W. W. (2019). AAV2.7m8 is a powerful viral vector for inner ear gene therapy. Nat. Commun. 10:427. doi: 10.1038/s41467-018-08243-1

Izumikawa, M. R., Minoda, K., Kawamoto, K. A., Abrashkin, D. L., Swiderski, D. F., Dolan, D. E., et al. (2005). Auditory hair cell replacement and hearing improvement by Atoh1 gene therapy in deaf mammals. Nat. Med. 11, 271-276. doi: 10.1038/nm1193

Jacques, B. E., Montgomery Iv, W. H., Uribe, P. M., Yatteau, A., Asuncion, J. D., Resendiz, G., et al. (2014). The role of $\mathrm{Wnt} / \beta$-catenin signaling in proliferation and regeneration of the developing basilar papilla and lateral line. Dev. Neurobiol. 74, 438-456. doi: 10.1002/dneu.22134

Jacques, B. E., Puligilla, C., Weichert, R. M., Ferrer-Vaquer, A., Hadjantonakis, A.K., Kelley, M. W., et al. (2012). A dual function for canonical Wnt/ $\beta$-catenin signaling in the developing mammalian cochlea. Development 139, 4395-4404. doi: $10.1242 / \mathrm{dev} .080358$

Jan, T. A., Chai, R., Sayyid, Z. N., van Amerongen, R., Xia, A., Wang, T., et al. (2013). Tympanic border cells are Wnt-responsive and can act as progenitors for postnatal mouse cochlear cells. Development 140, 1196-1206. doi: $10.1242 /$ dev.087528

Jen, H.-I., Hill, M. C., Tao, L., Sheng, K., Cao, W., Zhang, H., et al. (2019). Transcriptomic and epigenetic regulation of hair cell regeneration in the mouse utricle and its potentiation by Atoh1. eLife 8:e44328. doi: 10.7554/eLife.44328

Jiang, L., Romero-Carvajal, A., Haug, J. S., Seidel, C. W., and Piotrowski, T. (2014). Gene-expression analysis of hair cell regeneration in the zebrafish lateral line. Proc. Natl. Acad. Sci. U S A 111, E1383-E1392. doi: 10.1073/pnas.14028 98111 
Korrapati, S., Roux, I., Glowatzki, E., and Doetzlhofer, A. (2013). Notch signaling limits supporting cell plasticity in the hair cell-damaged early postnatal murine cochlea. PLoS One 8:e73276. doi: 10.1371/journal.pone.0073276

Ku, Y.-C., Renaud, N. A., Veile, R. A., Helms, C., Voelker, C. C. J., Warchol, M. E., et al. (2014). The transcriptome of utricle hair cell regeneration in the avian inner ear. J. Neurosci. 34, 3523-3535. doi: 10.1523/JNEUROSCI.2606-13.2014

Kuo, B. R., Baldwin, E. M., Layman, W. S., Taketo, M. M., and Zuo, J. (2015). In vivo cochlear hair cell generation and survival by coactivation of $\beta$-catenin and Atoh1. J. Neurosci. 35, 10786-10798. doi: 10.1523/JNEUROSCI.096715.2015

López-Arribillaga, E., Rodilla, V., Pellegrinet, L., Guiu, J., Iglesias, M., Roman, A. C., et al. (2015). Bmil regulates murine intestinal stem cell proliferation and self-renewal downstream of Notch. Development 142, 41-50. doi: $10.1242 /$ dev.107714

Lee, S. G., Huang, M., Obholzer, N. D., Sun, S., Li, W., Petrillo, M., et al. (2016). Myc and Fgf are required for zebrafish neuromast hair cell regeneration. PLoS One 11:e0157768. doi: 10.1371/journal.pone. 0157768

Lee, S., Song, J. -J., Beyer, L. A., Swiderski, D. L., Prieskorn, D. M., Acar, M., et al. (2020). Combinatorial Atoh1 and Gfil induction enhances hair cell regeneration in the adult cochlea. Sci. Rep. 10:21397. doi: 10.1038/s41598-02078167-8

Lewis, R. M., Keller, J. J., Wan, L., and Stone, J. S. (2018). Bone morphogenetic protein 4 antagonizes hair cell regeneration in the avian auditory epithelium. Hear. Res. 364, 1-11. doi: 10.1016/j.heares.2018.04.008

Li, W., Wu, J., Yang, J., Sun, S., Chai, R., Chen, Z.-Y., et al. (2015). Notch inhibition induces mitotically generated hair cells in mammalian cochleae via activating the Wnt pathway. Proc. Natl. Acad. Sci. U S A 112, 166-171. doi: 10.1073/pnas. 1415901112

Li, X.-J., and Doetzlhofer, A. (2020). LIN28B/let-7 control the ability of neonatal murine auditory supporting cells to generate hair cells through mTOR signaling. Proc. Natl. Acad. Sci. U S A 117, 22225-22236. doi: 10.1073/pnas. 2000417117

Liu, Z., Dearman, J. A., Cox, B. C., Walters, B. J., Zhang, L., Ayrault, O., et al. (2012). Age-dependent in vivo conversion of mouse cochlear pillar and Deiters' cells to immature hair cells by Atoh1 ectopic expression. J. Neurosci. 32, 6600-6610. doi: 10.1523/JNEUROSCI.0818-12.2012

Lu, N., Chen, Y., Wang, Z., Chen, G., Lin, Q., Chen, Z.-Y., et al. (2013). Sonic hedgehog initiates cochlear hair cell regeneration through downregulation of retinoblastoma protein. Biochem. Biophys. Res. Commun. 430, 700-705. doi: 10.1016/j.bbrc.2012.11.088

Lu, X., Sun, S., Qi, J., Li, W., Liu, L., Zhang, Y., et al. (2017). Bmil regulates the proliferation of cochlear supporting cells via the canonical Wnt signaling pathway. Mol. Neurobiol. 54, 1326-1339. doi: 10.1007/s12035-0169686-8

Lush, M. E., Diaz, D. C., Koenecke, N., Baek, S., Boldt, H., St Peter, M. K., et al. (2019). scRNA-Seq reveals distinct stem cell populations that drive hair cell regeneration after loss of Fgf and Notch signaling. eLife 8:e44431. doi: $10.7554 /$ eLife.44431

Ma, E. Y., Rubel, E. W., and Raible, D. W. (2008). Notch signaling regulates the extent of hair cell regeneration in the zebrafish lateral line. J. Neurosci. 28, 2261-2273. doi: 10.1523/JNEUROSCI.4372-07.2008

Masuda, M., Dulon, D., Pak, K., Mullen, L. M., Li, Y., Erkman, L., et al. (2011). Regulation of POU4F3 gene expression in hair cells by $5^{\prime}$ DNA in mice. Neuroscience 197, 48-64. doi: 10.1016/j.neuroscience.2011.09.033

Matern, M. S., Milon, B., Lipford, E. L., McMurray, M., Ogawa, Y., Tkaczuk, A., et al. (2020). GFIl functions to repress neuronal gene expression in the developing inner ear hair cells. Development 147:dev186015. doi: 10.1242/dev. 186015

Menendez, L., Trecek, T., Gopalakrishnan, S., Tao, L., Markowitz, A. L., Yu, H. V., et al. (2020). Generation of inner ear hair cells by direct lineage conversion of primary somatic cells. eLife 9:e55249. doi: 10.7554/eLife.55249

Mittal, R., Nguyen, D., Patel, A. P., Debs, L. H., Mittal, J., Yan, D., et al. (2017). Recent advancements in the regeneration of auditory hair cells and hearing restoration. Front. Mol. Neurosci. 10:236. doi: 10.3389/fnmol.2017.00236

Mizutari, K., Fujioka, M., Hosoya, M., Bramhall, N., Okano, H. J., Okano, H., et al. (2013). Notch inhibition induces cochlear hair cell regeneration and recovery of hearing after acoustic trauma. Neuron 77, 58-69. doi: 10.1016/j.neuron.2012. 10.032
Monzack, E. L., and Cunningham, L. L. (2013). Lead roles for supporting actors: critical functions of inner ear supporting cells. Hear. Res. 303, 20-29. doi: 10.1016/j.heares.2013.01.008

Moss, E. G., and Tang, L. (2003). Conservation of the heterochronic regulator Lin-28, its developmental expression and microRNA complementary sites. Dev. Biol. 258, 432-442. doi: 10.1016/s0012-1606(03)00126-x

Munnamalai, V., and Fekete, D. M. (2016). Notch-Wnt-Bmp crosstalk regulates radial patterning in the mouse cochlea in a spatiotemporal manner. Development 143, 4003-4015. doi: 10.1242/dev.139469

Ni, W., Lin, C., Guo, L., Wu, J., Chen, Y., Chai, R., et al. (2016). Extensive supporting cell proliferation and mitotic hair cell generation by in vivo genetic reprogramming in the neonatal mouse cochlea. J. Neurosci. 36, 8734-8745. doi: 10.1523/JNEUROSCI.0060-16.2016

Ornitz, D. M., and Itoh, N. (2015). The fibroblast growth factor signaling pathway. Wiley Interdiscip. Rev. Dev. Biol. 4, 215-266. doi: 10.1002/wdev.176

Padanad, M. S., Bhat, N., Guo, B., and Riley, B. B. (2012). Conditions that influence the response to Fgf during otic placode induction. Dev. Biol. 364, 1-10. doi: 10.1016/j.ydbio.2012.01.022

Pauley, S., Lai, E., and Fritzsch, B. (2006). Foxg1 is required for morphogenesis and histogenesis of the mammalian inner ear. Dev. Dyn. 235, 2470-2482. doi: $10.1002 /$ dvdy.20839

Romero-Carvajal, A., Acedo, J. N., Jiang, L., Kozlovskaja-Gumbrienè, A., Alexander, R., Li, H., et al. (2015). Regeneration of sensory hair cells requires localized interactions between the Notch and Wnt pathways. Dev. Cell 34, 267-282. doi: 10.1016/j.devcel.2015.05.025

Samarajeewa, A., Jacques, B. E., and Dabdoub, A. (2019). Therapeutic potential of wnt and notch signaling and epigenetic regulation in mammalian sensory hair cell regeneration. Mol. Ther. 27, 904-911. doi: 10.1016/j.ymthe.2019. 03.017

Schimmang, T. (2007). Expression and functions of FGF ligands during early otic development. Int. J. Dev. Biol. 51, 473-481. doi: 10.1387/ijdb. 072334ts

Shi, F., Hu, L., and Edge, A. S. B. (2013). Generation of hair cells in neonatal mice by $\beta$-catenin overexpression in Lgr5-positive cochlear progenitors. Proc. Nat. Acad. Sci. U. S. A. 110, 13851-13856. doi: 10.1073/pnas.1219 952110

Shi, F., Hu, L., Jacques, B. E., Mulvaney, J. F., Dabdoub, A., and Edge, A. S. B. (2014). $\beta$-Catenin is required for hair-cell differentiation in the cochlea. J. Neurosci. 34, 6470-6479. doi: 10.1523/JNEUROSCI.4305-13.2014

Shi, F., Kempfle, J. S., and Edge, A. S. B. (2012). Wnt-responsive Lgr5-expressing stem cells are hair cell progenitors in the cochlea. J. Neurosci. 32, 9639-9648. doi: 10.1523/JNEUROSCI.1064-12.2012

Shu, Y., Li, W., Huang, M., Quan, Y. -Z., Scheffer, D., Tian, C., et al. (2019) Renewed proliferation in adult mouse cochlea and regeneration of hair cells. Nat. Commun. 10:5530. doi: 10.1038/s41467-019-13157-7

Shyh-Chang, N., and Daley, G. Q. (2013). Lin28: primal regulator of growth and metabolism in stem cells. Cell Stem Cell 12, 395-406. doi: 10.1016/j.stem.2013. 03.005

Son, E. J., Ma, J.-H., Ankamreddy, H., Shin, J.-O., Choi, J. Y., Wu, D. K., et al. (2015). Conserved role of sonic Hedgehog in tonotopic organization of the avian basilar papilla and mammalian cochlea. Proc. Nat. Acad. Sci. U S A 112, 3746-3751. doi: 10.1073/pnas.1417856112

Tan, F., Chu, C., Qi, J., Li, W., You, D., Li, K., et al. (2019). AAV-ie enables safe and efficient gene transfer to inner ear cells. Nat. Commun. 10:3733. doi: 10.1038/s41467-019-11687-8

Tang, D., He, Y., Li, W., and Li, H. (2019). Wnt/B-catenin interacts with the FGF pathway to promote proliferation and regenerative cell proliferation in the zebrafish lateral line neuromast. Exp. Mol. Med. 51, 1-16. doi: 10.1038/s12276019-0247-x.

Tang, D., Lin, Q., He, Y., Chai, R., and Li, H. (2016). Inhibition of H3K9me2 reduces hair cell regeneration after hair cell loss in the zebrafish lateral line by down-regulating the Wnt and Fgf signaling pathways. Front. Mol. Neurosci. 9:39. doi: 10.3389/fnmol.2016.00039

Wallis, D., Hamblen, M., Zhou, Y., Venken, K. J. T., Schumacher, A., Grimes, H. L., et al. (2003). The zinc finger transcription factor Gfil, implicated in lymphomagenesis, is required for inner ear hair cell differentiation and survival. Development 130, 221-232. doi: 10.1242/dev. 00190 
Walters, B. J., Coak, E., Dearman, J., Bailey, G., Yamashita, T., Kuo, B., et al. (2017). In vivo interplay between p27(Kip1), GATA3, ATOH1 and POU4F3 converts non-sensory cells to hair cells in adult mice. Cell Rep. 19, 307-320. doi: 10.1016/j.celrep.2017.03.044

Wang, T., Chai, R., Kim, G. S., Pham, N., Jansson, L., Nguyen, D. -H., et al. (2015). Lgr5+ cells regenerate hair cells via proliferation and direct transdifferentiation in damaged neonatal mouse utricle. Nat. Commun. 6:6613. doi: $10.1038 /$ ncomms7613

Waqas, M., Zhang, S., He, Z., Tang, M., and Chai, R. (2016). Role of Wnt and Notch signaling in regulating hair cell regeneration in the cochlea. Front. Med. 10, 237-249. doi: 10.1007/s11684-016-0464-9

Wu, J., Li, W., Lin, C., Chen, Y., Cheng, C., Sun, S., et al. (2016). Co-regulation of the Notch and Wnt signaling pathways promotes supporting cell proliferation and hair cell regeneration in mouse utricles. Sci. Rep. 6:29418. doi: $10.1038 /$ srep29418

Yamamoto, N., Tanigaki, K., Tsuji, M., Yabe, D., Ito, J., and Honjo, T. (2006). Inhibition of Notch/RBP-J signaling induces hair cell formation in neonate mouse cochleas. J. Mol. Med. (Berl) 84, 37-45. doi: 10.1007/s00109-005-0706-9

Zarei, S., Zarei, K., Fritzsch, B., and Elliott, K. L. (2017). Sonic hedgehog antagonists reduce size and alter patterning of the frog inner ear. Dev. Neurobiol. 77, 1385-1400. doi: 10.1002/dneu.22544

Zhang, S., Liu, D., Dong, Y., Zhang, Z., Zhang, Y., Zhou, H., et al. (2019). Frizzled$9+$ supporting cells are progenitors for the generation of hair cells in the postnatal mouse cochlea. Front. Mol. Neurosci. 12:184. doi: 10.3389/fnmol. 2019.00184

Zhang, S., Zhang, Y., Dong, Y., Guo, L., Zhang, Z., Shao, B., et al. (2020). Knockdown of Foxg1 in supporting cells increases the trans-differentiation of supporting cells into hair cells in the neonatal mouse cochlea. Cell. Mol. Life Sci. 77, 1401-1419. doi: 10.1007/s00018-019-03291-2
Zhang, Y., Zhang, S., Zhang, Z., Dong, Y., Ma, X., Qiang, R., et al. (2020). Knockdown of Foxg1 in Sox9+ supporting cells increases the trans-differentiation of supporting cells into hair cells in the neonatal mouse utricle. Aging (Albany NY) 12, 19834-19851. doi: 10.18632/aging.104009

Zhong, C., Fu, Y., Pan, W., Yu, J., and Wang, J. (2019). Atoh1 and other related key regulators in the development of auditory sensory epithelium in the mammalian inner ear: function and interplay. Dev. Biol. 446, 133-141. doi: 10.1016/j.ydbio.2018.12.025

Zinn, E., Pacouret, S., Khaychuk, V., Turunen, H. T., Carvalho, L. S., AndresMateos, E., et al. (2015). In silico reconstruction of the viral evolutionary lineage yields a potent gene therapy vector. Cell Rep. 12, 1056-1068. doi: 10.1016/j. celrep.2015.07.019

Conflict of Interest: The authors declare that the research was conducted in the absence of any commercial or financial relationships that could be construed as a potential conflict of interest.

Publisher's Note: All claims expressed in this article are solely those of the authors and do not necessarily represent those of their affiliated organizations, or those of the publisher, the editors and the reviewers. Any product that may be evaluated in this article, or claim that may be made by its manufacturer, is not guaranteed or endorsed by the publisher.

Copyright (C) $2021 \mathrm{Xu}$ and Yang. This is an open-access article distributed under the terms of the Creative Commons Attribution License (CC BY). The use, distribution or reproduction in other forums is permitted, provided the original author(s) and the copyright owner(s) are credited and that the original publication in this journal is cited, in accordance with accepted academic practice. No use, distribution or reproduction is permitted which does not comply with these terms. 